\title{
Comparative bactericidal activity of four fluoroquinolones against Pseudomonas aeruginosa isolated from chronic suppurative otitis media
}

\author{
Katsuhisa Ikeda ${ }^{1 *}$, Shigeki Misawa² and Takeshi Kusunoki ${ }^{1}$
}

\begin{abstract}
Background: The aim of the present study was to evaluate the bactericidal activity of four new fluoroquinolones against current isolates of Pseudomonas aeruginosa from the patients with chronic suppurative otitis media (CSOM).

Methods: We examined bactericidal activity of four types of fluoroquinolones, garenoxacin (GRNX), levofloxacin (LVFX), ciprofloxacin (CPFX) and sitafloxacin (STFX) against current isolates of $P$. aeruginosa (50 strains).

Results: STFX exhibited the most potent activity of both $M C_{50}$ and $M C_{90}$, followed by CPFX, LVFX, and GRNX. The number of GRNX-resistant strains was significantly greater than those of LVFX, CPFX, and STFX $(P<0.05)$.

Conclusion: STFX showed the most potent activity against $P$. aeruginosa for recent pathogens recovered from CSOM as compared with the others, suggesting that the clinical application of topical STFX would be useful to prevent the emergence of resistant mutants of $P$. aeruginosa.
\end{abstract}

Keywords: Fluoroquinolone, Pseudomonas aeruginosa, Chronic suppurative otitis media, Bactericidal activity, Minimum inhibitory concentration

\section{Background}

Chronic suppurative otitis media (CSOM) is defined as tympanic membrane perforation with ear discharge or otorrhea present continuously for at least 2 weeks $[1,2]$, and can result in thickening of the middle ear mucosa and mucosal polyps. CSOM continues for months or years with increasing hearing impairment; it can lead to life-threatening infective complications $[3,4]$. The commonly isolated microorganisms are Pseudomonas aeruginosa and Staphylococcus aureus; P. aeruginosa has been particularly implicated in the causation of bony necrosis and mucosal disease. Newer third- and fourth-generation fluoroquinolones often possess excellent in vitro activity against the most common respiratory pathogens [5].

In the present study, we evaluated the bactericidal activity of four new fluoroquinolones against current isolates of $P$. aeruginosa from patients with CSOM.

\footnotetext{
* Correspondence: ike@juntendo.ac.jp

${ }^{1}$ Department of Otorhinolaryngology, Juntendo University Faculty of

Medicine, 2-1-1 Hongo, Bunkyo-ku, Tokyo 113-8421, Japan

Full list of author information is available at the end of the article
}

\section{Methods}

We collected P.aeruginosa isolated from clinical specimens taken from the middle ear perforation under a microscope in patients with CSOM at the Department of Otorhinolaryngology, Juntendo University Hospital from January in 2010 to March in 2013. Sampling was random and continuous and those who had recently used local or systemic antibiotics were excluded. The specimens for all bacterial culture were promptly transported in culturette tubes kept moist with Stuart's bacterial transport medium. The study was approved by the ethics committee of the Juntendo University Faculty of Medicine. The informed consent was not required since all data were collected as part of routine diagnosis and treatment, and were retrospectively analyzed. Total number of strains of P.aeruginosa was 50. The subjects from whom P.aeruginosa was recovered were 32 males and 18 females ranging in age from 1 to 90 years (mean age 51.7 years).

For antimicrobial susceptibility testing, we measured the minimum inhibitory concentration $(\mathrm{MIC})$ by the

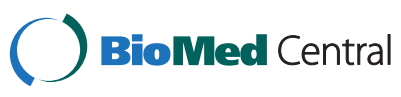

(c) 2015 Ikeda et al. Open Access This article is distributed under the terms of the Creative Commons Attribution 4.0 International License (http://creativecommons.org/licenses/by/4.0/), which permits unrestricted use, distribution, and reproduction in any medium, provided you give appropriate credit to the original author(s) and the source, provide a link to the Creative Commons license, and indicate if changes were made. The Creative Commons Public Domain Dedication waiver (http://creativecommons.org/publicdomain/zero/1.0/) applies to the data made available in this article, unless otherwise stated. 


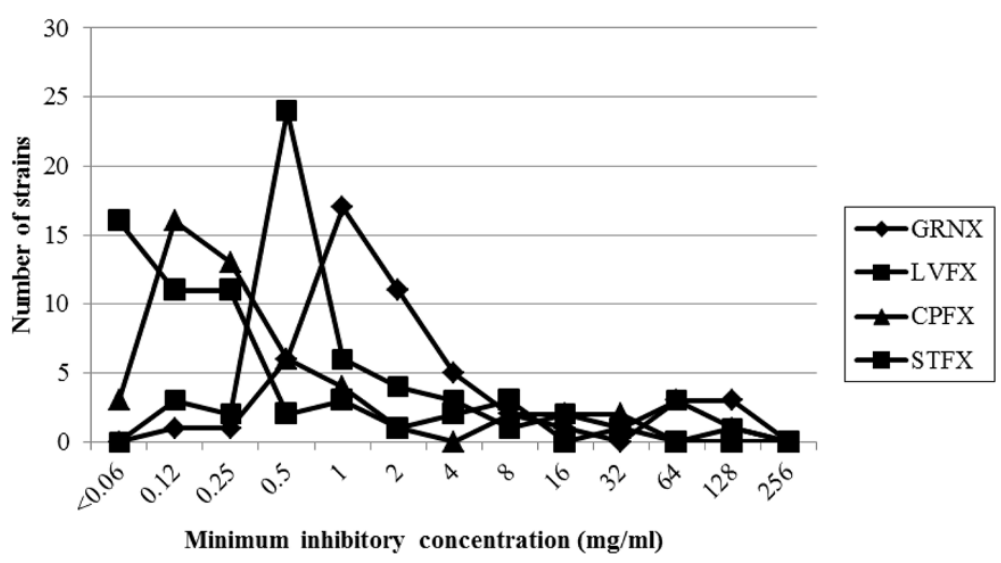

Fig. 1 The distribution of minimum inhibitory concentrations of Pseudomonas aeruginosa

broth microdilution method, complying with the Clinical and Laboratory Standards Institute (CLSI) standard [6]. Drug-containing agar plates were inoculated with $5 \mu \mathrm{l}$ of each specimen and the plates were incubated for 16$20 \mathrm{~h}$ at $35 \pm 2{ }^{\circ} \mathrm{C}$. The MIC was defined as the lowest drug concentration that prevented visible growth of the bacteria. The $\mathrm{MIC}_{50}$ and $\mathrm{MIC}_{90}$ were defined as the MICs at which $50 \%$ and $90 \%$ of isolates are inhibited, respectively. The strains were classified according to the CLSI criteria [7]. Sensitivity to four types of fluoroquinolones, garenoxacin (GRNX), levofloxacin (LVFX), ciprofloxacin (CPFX) and sitafloxacin (STFX), was tested and was classified according to the CLSI criteria [8]. Namely, the P.aeruginosa strains were classified as GRNX-sensitive $(\mathrm{MIC} \leq 1 \mu \mathrm{g} / \mathrm{ml})$, -intermediate $(\mathrm{MIC}=2 \mu \mathrm{g} / \mathrm{ml})$, resistant $\quad(\mathrm{MIC} \geq 4 \quad \mu \mathrm{g} / \mathrm{ml}) \quad$ strains; LVFX-sensitive $(\mathrm{MIC} \leq 2 \mu \mathrm{g} / \mathrm{ml})$, -intermediate $(\mathrm{MIC}=2 \mu \mathrm{g} / \mathrm{ml})$, resistant $(\mathrm{MIC} \geq 8 \mu \mathrm{g} / \mathrm{ml}$ ) strains; CPFX-sensitive (MIC $\leq 1 \mu \mathrm{g} /$ $\mathrm{ml})$, -intermediate (MIC $=2 \mu \mathrm{g} / \mathrm{ml})$, resistant $(\mathrm{MIC} \geq 4 \mu \mathrm{g} /$ $\mathrm{ml}$ ) strains; STFX-sensitive (MIC $\leq 1 \mu \mathrm{g} / \mathrm{ml}$ ), -intermediate $(\mathrm{MIC}=2 \mu \mathrm{g} / \mathrm{ml})$, resistant $(\mathrm{MIC} \geq 4 \mu \mathrm{g} / \mathrm{ml})$ strains.

Statistical analyses were evaluated using StatMate IV for Windows. Chi-square test was used to compare the susceptibility for 4 fluoroquinolones. Results were considered to be significant if the $P$ values were less than 0.05 .

\section{Results}

The Fig. 1 shows the distribution of MIC for the 4 fluoroquinolones against $P$. aeruginosa. Among the 4 fluoroquinolones tested here, STFX exhibited the

Table $1 \mathrm{MIC}_{50}$ and $\mathrm{MIC}_{90}$ of Pseudomonas aeruginosa

\begin{tabular}{lll}
\hline & $\mathrm{MIC}_{50}(\mu \mathrm{g} / \mathrm{ml})$ & $\mathrm{MIC}_{90}(\mu \mathrm{g} / \mathrm{ml})$ \\
\hline GRNX & 1 & 64 \\
LVFX & 0.5 & 32 \\
CPFX & 0.25 & 16 \\
STFX & 0.12 & 4 \\
\hline
\end{tabular}

most potent activity at both $\mathrm{MIC}_{50}$ and $\mathrm{MIC}_{90}$, followed by CPFX, LVFX, and GRNX (Table 1). Table 2 shows a summary of the fluoroquinolonesensitive, -intermediate, -resistant strains of $P$. aeruginosa. The number of GRNX-resistant strains was significantly greater than those of LVFX, CPFX, and STFX $(P<0.05)$.

\section{Discussion}

This is the first report to compare the bactericidal activity of 4 fluoroquinolones, namely GRNX, LVFX, CPFX, and SIFX, against $P$. aeruginosa recovered from CSOM. A nationwide surveillance of antimicrobial susceptibility of bacterial lower respiratory pathogens from patients in Japan between 2006 and 2007 reported that, in a total 103 P. aeruginosa strains, CPFX among 6 fluoroquinolones showed the most potent activity and that the other fluoroquinolones showed strong activity but were suggested to have met with partial resistance [9]. However, this report did not include the antimicrobial susceptibility of STFX. The high sensitivity rate for $P$. aeruginosa to CPFX in the present study is well comparable to that reported in recent studies [10-15], whereas there are no previous data available on the susceptibility of $P$. aeruginosa isolated from CPOM to GRNX, LVFX, and STFX. The present study clearly demonstrated that STFX showed the most potent activity against $P$. aeruginosa for recent pathogens recovered from CSOM as compared with GRNX, LVFX, and CPFX.

Table 2 The susceptibility of Pseudomonas aeruginosa to fluoroquinolones

\begin{tabular}{llll}
\hline & \multicolumn{2}{l}{ Number of strains (\%) } \\
\cline { 2 - 4 } & Susceptible & Intermediate & Resistant \\
\hline GRNX & $25(50)$ & $11(22)$ & $14(28)$ \\
LVFX & $39(78)$ & $3(6)$ & $8(16)$ \\
CPFX & $42(82)$ & $1(2)$ & $7(14)$ \\
STFX & $43(86)$ & $1(2)$ & $6(12)$ \\
\hline
\end{tabular}


The isolation rate of $P$. aeruginosa strains resistant to antibiotics has increased recently, making it more difficult to select adequate antibiotics. Resistance to fluoroquinolones in the present study ranged from 12 to $28 \%$, although the MIC of STFX was less than $32 \mu \mathrm{g} / \mathrm{ml}$. Two major mechanisms $[16,17]$ may lead to fluoroquinolone resistance to $P$. aeruginosa; i) modification of the primary target (DNA gyrase) and secondary target (topoisomerase IV) by point mutations in gyrA/gyrB and parC/par genes, respectively, and ii) four efflux systems identified in $P$. aeruginosa.

In the absence of systemic infection or serious underlying disease, first line pharmacologic treatment for most patients with CSOM usually entails oto-topical fluoroquinolones such as ofloxacin and CPFX. High concentrations are pharmaco-dynamically important for antibiotics known to have a concentration-dependent mechanism of action such as fluoroquinolones. Consequently, the concentration of delivered topical fluoroquinolones seems always well above the MIC of $P$. aeruginosa, making the emergence of bacterial resistance extremely unlikely [18]. Moreover, the present study may encourage the clinical application of topical STFX as a treatment for CSOM in order to prevent the emergence of resistant mutants of $P$. aeruginosa.

\section{Conclusion}

STFX showed the most potent activity against $P$. aeruginosa for recent pathogens recovered from CSOM as compared with the others, supporting the clinical application of topical STFX in order to prevent the emergence of resistant mutants of $P$. aeruginosa.

\section{Abbreviations \\ CSOM: Chronic suppurative otitis media; LVFX: Levofloxacin; \\ GRNX: Garenoxacin; CPFX: Ciprofloxacin; STFX: Sitafloxacin; MIC: Minimum inhibitory concentration; CLSI: Clinical and Laboratory Standards Institute.}

\section{Competing interests}

The authors have no funding, financial relationships or conflict of interest to disclose.

This material has never been published and is not currently under evaluation in any other peer-reviewed publication.

\section{Authors' contributions}

$\mathrm{KI}$ and TK were involved in all stages of the study. NM was involved in measurement of MIC. All authors gave final approval for the publication of this manuscript. All authors read and approved the final manuscript.

\section{Acknowledgements}

The authors thank Mr. Brent Bell for correcting the English of the manuscript.

\section{Author details}

${ }^{1}$ Department of Otorhinolaryngology, Juntendo University Faculty of Medicine, 2-1-1 Hongo, Bunkyo-ku, Tokyo 113-8421, Japan. ${ }^{2}$ Microbiology Laboratory, Juntendo University Faculty of Medicine, 2-1-1 Hongo, Bunkyo-ku, Tokyo 113-8421, Japan.

Received: 17 April 2015 Accepted: 5 October 2015

Published online: 14 October 2015

\section{References}

1. WHO and UNICEF. Management of children illness. Gneva: WHO/CDR/95.14A-LHO; 2004.

2. Meyerhoff WL. Pathology of chronic suppurative otitis media. Ann Otol Rhinol Laryngol. 1988;97 suppl 131:21-4.

3. Yorgancilar E, Yildirim M, Gun R, Bakir S, Tekin R, Gocmez C, et al. Complications of chronic suppurative otitis media: a retrospective review. Eur Arch Otorhinolaryngol. 2013;270:69-76.

4. Mostafa BE, El Fiky LM, El Sharnouby MM. Complications of suppurative otitis media: still a problem in the 21st century. ORL J Otorhinolaryngol Relat Spec. 2009;71:87-92.

5. Shams WE, Evans ME. Guide to selection of fluoroquinolones in patients with lower respiratory tract infections. Drugs. 2005;65:949-91.

6. Institute CaLS. Methods for dilution antimicrobial susceptibility tests for bacteria that grow aerobically; approved standard. Seventh edition. M7-A7 Wayne: 2006.

7. Institute CaLS. Performance standards for antimicrobial susceptibility testing; 17th informational supplement. M100-S17 Wayne PA: Clinical and Laboratory Standards Institute; 2007.

8. Institute CLS. Performance standards for antimicrobial susceptibility testing; 22nd informational supplement. Wayne, PA: Document M100-S22 Clinical Laboratory Standards Institute; 2012

9. Watanabe A, Yanagihara K, Matsumoto T, Kohno S, Aoki N, Oguri T, et al. Nationwide surveillance of bacterial respiratory pathogens conducted by the Surveillance Committee of Japanese Society of Chemotherapy, Japanese Association for Infectious Diseases, and Japanese Society for Clinical Microbiology in 2009: general view of the pathogens' antibacterial susceptibility. J Infect Chemother. 2012;18:609-20.

10. Orji FT, Dike BO. Observations on the current bacteriological profile of chronic suppurative otitis media in South eastern Nigeria. Ann Med Health Sci Res. 2015:5:124-8.

11. Sharma K, Aggarwal A, Khurana PM. Comparison of bacteriology in bilaterally discharging ears in chronic suppurative otitis media. Indian J Otolaryngol Head Neck Surg. 2010;62:153-7.

12. Lee SK, Park DC, Kim MG, Boo SH, Choi YJ, Byun JY, et al. Rate of isolation and trends of antimicrobial resistance of multidrug resistant pseudomonas aeruginosa from otorrhea in chronic suppurative otitis media. Clin Exp Otorhinolaryngol. 2012;5:17-22.

13. Deb T, Ray D. A study of the bacteriological profile of chronic suppurative otitis media in agartala. Indian J Otolaryngol Head Neck Surg. 2012;64:326-9.

14. Afolabi OA, Salaudeen AG, Ologe FE, Nwabuisi C, Nwawolo CC. Pattern of bacterial isolates in the middle ear discharge of patients with chronic suppurative otitis media in a tertiary hospital in North central Nigeria. Afr Health Sci. 2012;12:362-7.

15. Vishwanath S, Mukhopadhyay C, Prakash R, Pillai S, Pujary K, Pujary P. Chronic suppurative otitis media: Optimizing initial antibiotic therapy in a tertiary care setup. Indian J Otolaryngol Head Neck Surg. 2012;64:285-9.

16. Hooper DC. Emerging mechanisms of fluoroquinolone resistance. Emerg Infect Dis. 2001;7:337-41.

17. Masuda N, Sakagawa E, Ohya S, Gotoh N, Tsujimoto H, Nishino T. Substrate specificities of MexAB-OprM, MexCD-OprJ, and MexXY-oprM efflux pumps in Pseudomonas aeruginosa. Antimicrob Agents Chemother. 2000;44:3322-7.

18. Daniel SJ. Topical treatment of chronic suppurative otitis media. Curr Infect Dis Rep. 2012;14:121-7. 